\title{
A Case of Dentinogenic Ghost Cell Tumor
}

\author{
Jon Michael Vincent Soon ${ }^{1}$ and Jose Carnate Jr., ${ }^{1,2}$
}

${ }^{1}$ Department of Laboratory Medicine and Pathology, The Medical City, Pasig City, Philippines

${ }^{2}$ Department of Pathology, College of Medicine, University of the Philippines Manila

\section{ABSTRACT}

Among the ghost cell lesions, Dentinogenic Ghost Cell Tumors (DGCT) are among the rarest. We report a case of a 45-year-old Filipino man, who presented with a right mandibular mass. Microscopic examination showed a solid neoplasm composed of islands of odontogenic epithelium with areas showing aberrant keratinization forming ghost cells and dentinoid material. We also discuss the pertinent differential diagnosis of ghost cell-containing odontogenic tumors. We report this case due to its rarity, its morphological resemblance to ameloblastoma, and its potential for malignant transformation.

Key words: dentinogenic ghost cell tumor, odontogenic cyst, ghost cells, odontogenic tumors

ISSN 2507-8364 (Online)

Printed in the Philippines.

Copyright $($ C 2021 by the PJP.

Received: 4 May 2021

Accepted: 26 May 2021.

Published online first: 5 August 2021.

https://doi.org/10.21141/PJP.2021.02

Corresponding author: Jon Michael Vincent G. Soon, MD, MBA E-mail:jon.michael.soon@gmail.com

\section{INTRODUCTION}

Dentinogenic ghost cell tumors are a rare form of ghost cell lesion, accounting for less than $3 \%$ of cases. It is described as a locally invasive tumor and was considered as a solid variant of calcifying odontogenic cyst. Here we present a case of a 45-year-old, Filipino male, with a history of right mandibular mass.

\section{DISCUSSION}

A 45-year-old Filipino male presented with a three month history of right mandibular mass. Examination revealed that it was non-tender, non-erythematous, with no pain on salivation, and no difficulty eating or swallowing. A CT scan revealed an expansile hypodense lesion involving the mandibular ramus and body (Figure 1). The clinical impression was that of an ameloblastoma. The patient underwent a marginal mandibulectomy and the specimen was sent for histopathologic evaluation.

The specimen consisted of two irregularly-shaped soft to gritty tissues which measured $2.6 \times 1.5 \times 1.0$ and 4.5 x 3.0 × $2.0 \mathrm{~cm}$. Microscopic examination showed a solid neoplasm composed of islands of odontogenic epithelium with areas showing aberrant keratinization forming ghost cells and dentinoid material (Figure 2). The odontogenic epithelium resembles ameloblastoma, with columnar to cuboidal cells, hyperchromatic nuclei, peripheral palisading and reverse nuclear polarity (Figure 3). The presence of aberrant keratinization with calcification forming abundant ghost cells (Figure 4), and dentinoid material surrounding epithelial cells were noted (Figure 5). Based on these features, a diagnosis of dentinogenic ghost cell tumor (DGCT) was rendered.

The rarest among the ghost cell lesions, DGCT accounts for less than $3 \%$ of cases. ${ }^{1}$ It can involve a wide age range, with a peak incidence at $40-60$ years, with a male predilection. ${ }^{1,2}$ Most commonly, it occurs as an intraosseous lesion, affecting the posterior maxilla and mandible. ${ }^{1,2}$ The size of the mass varies between one to more than ten centimeters in diameter, but is frequently asymptomatic. ${ }^{2}$ Etiogenesis remains unclear, but is attributed to cell rests 


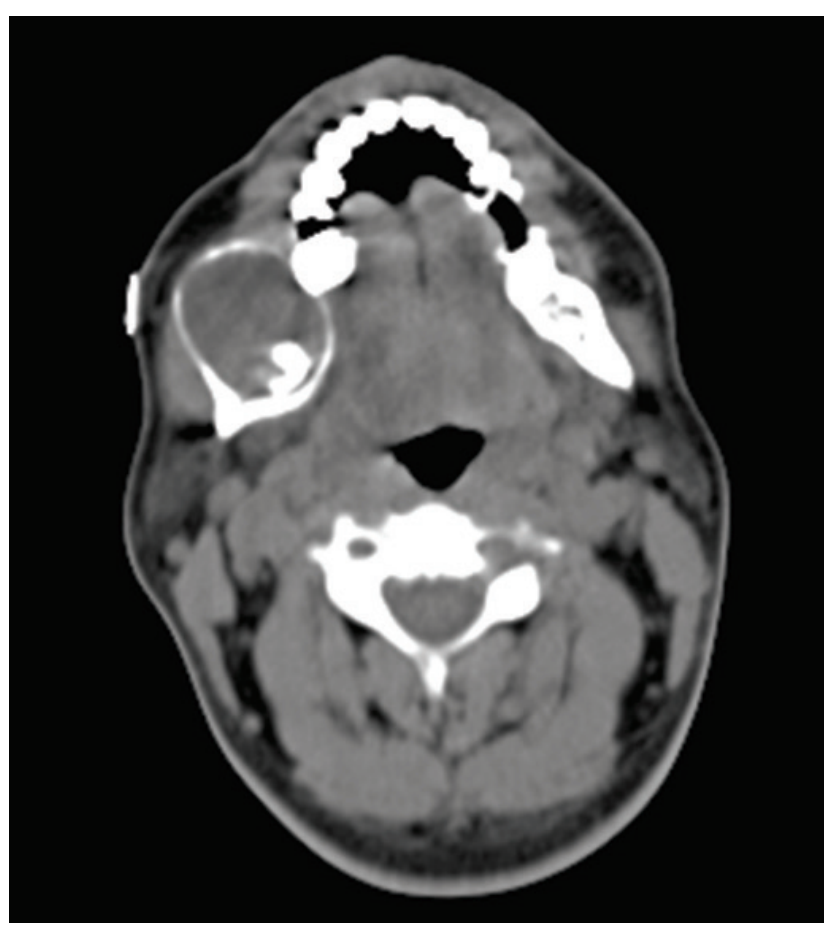

Figure 1. CT scan of the mandible shows a $4.9 \times 3.5 \times 4.4 \mathrm{~cm}$ expansile, predominantly hypodense lesion in the right hemimandible, involving the mandibular ramus and body associated with cortical thinning.

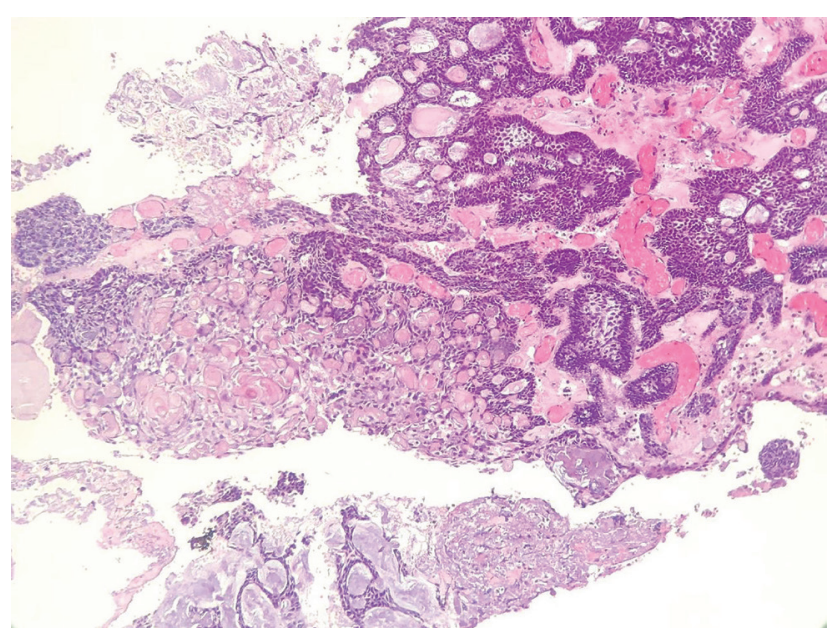

Figure 2. Islands of odontogenic epithelium with areas showing aberrant keratinization forming ghost cells and dentinoid material (H\&E, 100x).

of Serres or the surface epithelium. ${ }^{2}$ Molecular findings reveal that mutations in $\beta$-catenin, a transcriptional activator of the Wnt pathway, are associated with tumors with ghost cells ${ }^{3}$. Mutations in B-catenin found in DGCTs have been shown to correlate with $\beta$-catenin immunohistochemistry, however these are not utilized in the diagnosis of DCGTs, the diagnosis being largely made on the basis of morphology. ${ }^{3,4}$

Described as a locally invasive neoplasm, DGCTs are characterized by sheets and rounded islands of odontogenic epithelial cells, which resemble ameloblastoma, seen in a mature connective tissue. ${ }^{1,2}$ The resemblance includes

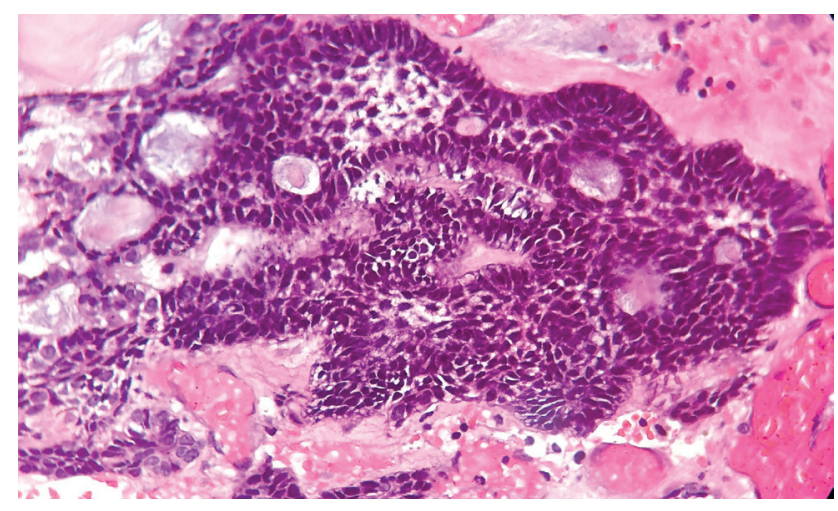

Figure 3. Odontogenic epithelium with peripheral palisading and reverse polarity. Some microcystic spaces are present (H\&E, 400x).

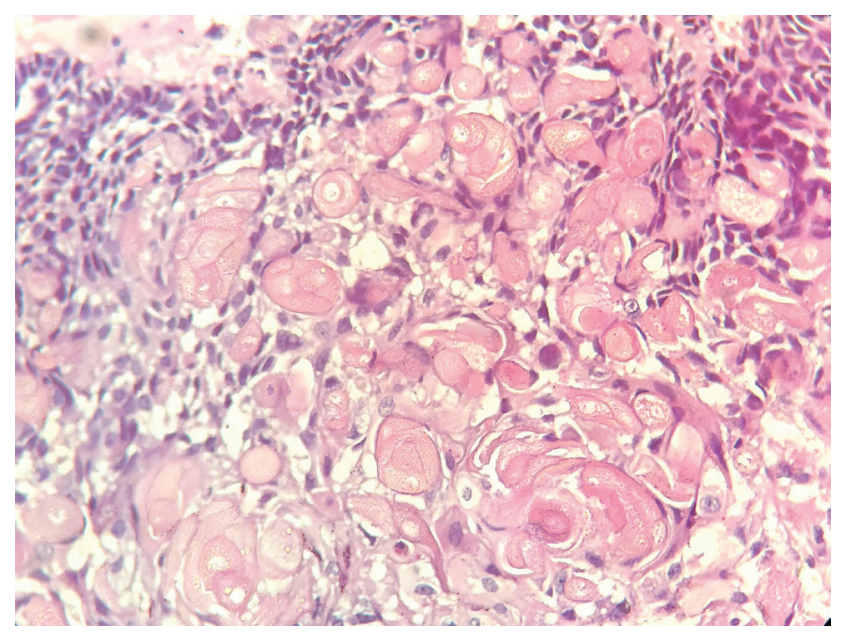

Figure 4. Aberrant keratinization with calcification forming abundant ghost cells (H\&E, 400x).

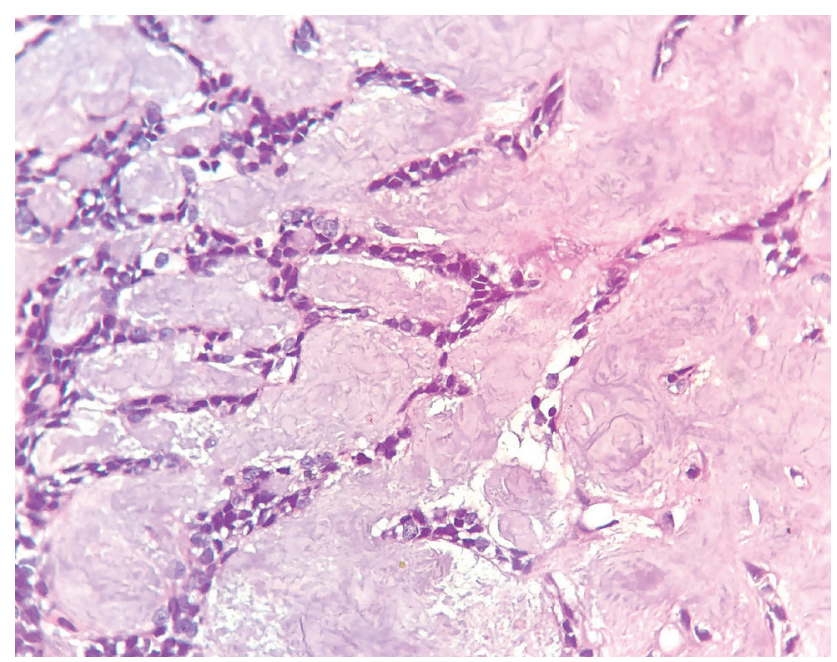

Figure 5. Dentinoid material forming around epithelial cells (H\&E, 400x).

characteristic peripheral palisading, reverse nuclear polarization, and presence of a stellate reticulum within the cell nests. In addition, the other characteristic features of DGCTs are the presence of ghost cells and dentinoid material. ${ }^{1}$ While the exact origin of the ghost 
cells is unclear, it should be noted that they are not pathognomonic, and may also be found in other neoplasms such as ameloblastoma. ${ }^{2}$ However, the proportion of ghost cells in DGCTs is much higher (>1-2\%) than that in ameloblastoma, making it together with the presence of dentinoid features necessary to the diagnosis of DGCT. ${ }^{1}$

Pertinent differential diagnoses of DGCTs, other than ameloblastoma, include calcifying odontogenic cyst, and ghost cell odontogenic carcinoma. As the name suggests, calcifying odontogenic cysts are unicystic compared to DGCTs, which are solid tumors. ${ }^{1}$ On the other hand, ghost cell odontogenic carcinoma may arise from a DGCT or from a calcifying odontogenic cyst precursor, but is differentiated by cytologic evidence of malignancy. ${ }^{1}$ This includes mitosis, pleomorphism, hyperchromasia, necrosis and an infiltrative growth pattern. ${ }^{1}$

DGCTs can be treated surgically through enucleation or surgical resection. ${ }^{2}$ However due to the small number of reported cases, there is no consensus for an optimal treatment. ${ }^{1}$ Long term follow up is recommended due to a recurrence rate of up to $73 \%$ in conservatively treated cases. ${ }^{1}$ Cases of malignant transformation have also been reported. ${ }^{1}$

\section{CONCLUSION}

DGCT is a rare tumor that shares morphological features with other ghost cell-containing odontogenic tumors and with ameloblastoma with which it may be confused. Also, owing to its rarity, there is currently no consensus on an optimal treatment with long term follow up being recommended due to observations of malignant transformation. Reporting these cases may help further elucidate the long-term behavior and most appropriate management of the entity.

\section{ETHICAL CONSIDERATION}

Ethics clearance was obtained for the case. The authors ensured that all identifying marks have been removed.

\section{STATEMENT OF AUTHORSHIP}

All authors certified fulfillment of ICMJE authorship criteria

\section{AUTHOR DISCLOSURE}

The authors declared no conflict of interest.

\section{FUNDING SOURCE}

None.

\section{REFERENCES}

1. Carlos R, Ledesma-Montes C. Dentinogenic ghost cell tumour. In: El-Naggar AK, Chan JKC, Grandis JR, Takata T, Slootweg PJ. WHO classification of head and neck tumors, 4th ed. IARC: Lyon; 2017.

2. Bafna SS, Joy T, Tupkari JV, Landge JS. Dentinogenic ghost cell tumor. J Oral Maxillofac Pathol. 2016; 20(1):163. PMID: 27194885. PMCID: PMC4860925. https://doi.org/10.4103/0973-029X.180985.

3. Bilodeau EA, Prasad JL, Alawi F, Seethala RR. Molecular and genetic aspects of odontogenic lesions. Head Neck Pathol. 2014;8(4):400-10. PMID: 25409852. PMCID: PMC4245404. https://doi.org/ 10.1007/s12105-014-0588-7.

4. Kim SA, Ahn SG, Kim SG, et al. Investigation of the $\beta$-catenin gene in a case of dentinogenic ghost cell tumor. Oral Surg Oral Med Oral Pathol Oral Radiol Endod. 2007;103(1):97-101. PMID: 17178501. https://doi.org/10.1016/j.tripleo.2005.10.037

\footnotetext{
Disclaimer: This journal is OPEN ACCESS, providing immediate access to its content on the principle that making research freely available to the public supports a greater global exchange of knowledge. As a requirement for submission to the PJP, all authors have accomplished an AUTHOR FORM, which declares that the ICMJE criteria for authorship have been met by each author listed, that the article represents original material, has not been published, accepted for publication in other journals, or concurrently submitted to other journals, and that all funding and conflicts of interest have been declared. Consent forms have been secured for the publication of information about patients or cases; otherwise, authors have declared that all means have been exhausted for securing consent.
} 